\title{
DOI 10.26886/2523-6946.1(1)2017.3
}

UDC 616.594.14-092.19

THE ROLE OF CYTOKINE REGULATORY SIGNALING MOLECULES IN THE FOCAL ALOPECIA PATHOGENESIS

\section{Salim Khadhri, PhD, MD}

Tunisia (TN)

The subject matter of this research is the cytokine profile and clinical features of alopecia areata. The aim of the work is to study the role of pro, anti-inflammatory and regulatory cytokines in the development of clinical manifestations of focal alopecia on the scalp and disorders of the psychophysiological state of patients. Using the immunoenzyme method with the patients suffering alopecia areata we defined changes of blood cytokine regulatory signaling molecules: a pro-inflammatory cytokine of tumor necrosis factor-alpha (TNF $\alpha$ - an increase in the average, 3.7 times, $p$ <0.001), an anti-inflammatory cytokine interleukin-10 (IL-10 - decrease in the level, on average, by 1.2 times, $p$ <0.05), regulatory cytokine transforming growth factor-beta (TGF $\beta$ - decrease in the level, on average, 1.14 times $-p>0.05)$. Besides the known latest data about the effect of these cytokines on the regulation of hair follicles work, their significant correlation links with the indices of the patients' psychophysiological state were found; while related to $I L-10$, they were of direct moderate power $(r=$ 0.38), and for TNFa negative moderate force ( $r=-0.47)$.

Keywords: alopecia areata, cytokines, disorders of the psychophysiological state.

Салим Хадри, доктор медицины и фрилософрии. Роль цитокиновых регуляторных сигнальных молекул в патогенезе очаговой алопеции / Тунис 
Предмет исследования - цитокиновый профриль и особенности клинического течения очаговой алопеции. Цель работы - изучение роли про-, противовоспалительных и регуляторных цитокинов $в$ развитии клинических проявлений очаговой алопеции на волосистой части головы и нарушений психофизиологического состояния больных. Иммунофрерментным методом у больных очаговой алопецией установлено наличие изменений в крови цитокиновых регуляторных сигнальных молекул: провоспалительного цитокина фрактора некроза опухоли-альфра (TNFa - увеличение содержания, в среднем, в 3,7 раза; p<0,001), противовоспалительного цитокина интерлейкина-10 (IL-10 - снижение уровня, в среднем, в 1,2 раза; p<0,05), регуляторного цитокина трансфрормирующего фрактора роста-бета (TGFß - снижение уровня, в среднем, в 1,14 раза $p>0,05)$. Кроме известных современных данных о влиянии этих цитокинов на регуляцию работы волосяных фолликулов, выявлены uх значимые корреляционные связи с показателями психофизиологического состояния больных, причем в отношении IL10 они были прямой умеренной силы (r=0,38), а в отношении TNFaобратной умеренной силы ( $r=-0,47)$.

Ключевые слова: очаговая алопеция, цитокины, нарушения психофизиологического состояния.

Введение. Очаговая алопеция относится к заболеваниям человека, при котором не только имеются проявления выпадения волос, но и наблюдаются значительные психоэмоциональные нарушения у больных, которые приводят к снижению качества их жизни. Частота этого заболевания среди дерматозов составляет от 3 до $12 \%$ в разных странах мира [1-3]. В отношении термина «очаговая алопеция» и сущности заболевания V. Price [4] считает, что это 
поражение кожи имеет аутоиммунный генез и вокруг волосяного фолликула формируется характерный клеточный инфильтрат из CD8 ${ }^{+}$, $\mathrm{CD}^{+}$лимфоцитов, макрофрагов, клеток Лангерганса. В то же время известно, что важную сигнальную роль в межклеточных отношениях играют цитокины, однако, в отношении их роли в патогенезе очаговой алопеции имеются противоречивые данные [5-7]. Это диктует необходимость дальнейшего изучения роли различных классов цитокинов в патогенезе данного заболевания.

Цель работы - изучение роли про-, противовоспалительных и регуляторных цитокинов в развитии клинических проявлений очаговой алопеции на волосистой части головы и нарушений психофизиологического состояния больных.

Материалы и методы. Под наблюдением находилось 40 больных очаговой алопецией в возрасте от 21 до 60 лет, мужчин - 25 (62,5\%), женщин - 15 (37,5\%), которым проводились общие клиниколабораторные исследования, а так же применялись психологические, иммуноферментные и статистические методы обследований. Для определения психофизиологического состояния пациентов, с целью установления у них невротических расстройств, использовался психологический метод с помощью специального опросника [8], который адаптирован к больным дерматологического профиля. При наличии невротических расстройств у пациентов диагностировались так называемые основные и дополнительные симптомы. К первым (основным) из них относили: снижение настроения на протяжении 2 или более недель, потеря интереса и ощущения удовлетворения практически во всех сферах деятельности, психомоторная заторможенность или снижение психической и физической активности, снижение трудоспособности, прежнего уровня общения (или наоборот: суетливость, неусидчивость, неспособность к 
конструктивной и целенаправленной деятельности); ко вторым (дополнительным) относили: снижение способности к концентрации внимания, снижение самооценки и уверенности в себе, наличие идей вины и унижения, пессимистическое видение будущего, расстройства сна, снижение аппетита, суицидальные франтазии, мысли, намерения. Для статистического анализа степени расстройств психофизиологического состояния их оценивали в условных баллах (у. б.), при этом считали невротические изменения: «легкой» степени выражености (1у. б.), если констатировали по крайней мере 2 основных невротических симптома и 2 - дополнительных; «умеренной» степени (2 у. б.), соответственно - 2 основных и 3-4 дополнительных; наличие всех 3 основных невротических симптомов и не менее 4 дополнительных оценивали как «тяжелую» (3 у. б.) степень изменений психофизиологического состояния.

Исследование содержания в крови цитокинов (интерлейкин-10 IL-10, фрактор некроза опухоли-альфа - TNFa, трансформирующий фактор роста-бета - TGF $\beta$ ) проводили иммуноферментным методом с использованием соответствующих коммерческих тест-систем: TGF $\beta$ Bender MedSystem (AT), TNFa, IL-10 - Biosourse (BE). Контрольную группу (практически здоровые лица) составили 20 добровольцев, репрезентативных по полу и возрасту.

Статистическая обработка полученных результатов исследования проводилась с помощью пакета прикладных программ “Office Professional 2000” фрирмы Microsoft Corporation; при этом вычислялись средние значения показателей (М), их отклонения (m), достоверность разницы между данными сравнения соответствующих рядов (р), корреляционные коэффрициенты зависимости клинических и лабораторных результатов исследования (r). 
Работа выполнялась в рамках программы подготовки зарубежных аспирантов в Запорожском государственном медицинском университете и является фрагментом комплексной НДР (0107U005122, UA).

Результаты и их обсуждение. У большинства больных очаговой алопецией $(29$ - 72,5\%) длительность заболевания находилась в пределах от 6 месяцев до 3 лет. Наиболее частыми причинами, которые способствовали возникновению очагов выпадения волос на волосистой части головы, были нервно-психические факторы (32 $80 \%$ ). Заболевание характеризовалось наличием очагов выпадения волос на волосистой части головы округлой или овальной формы от 2 до 12 см в диаметре, резко ограниченных от участков неповрежденной кожи с зоной расшатанных волос по краю.

Иммунофрерментные исследования содержания цитокинов разного функционального назначения в крови больных очаговой алопецией выявили: достоверное ( $p<0,001)$ повышение уровня TNFa $(21,65 \pm 1,19$ пг/мл) по сравнению со здоровыми лицами (контрольная группа $5,85 \pm 0,76$ пг/мл); достоверное $(p<0,05)$ снижение уровня в крови IL-10

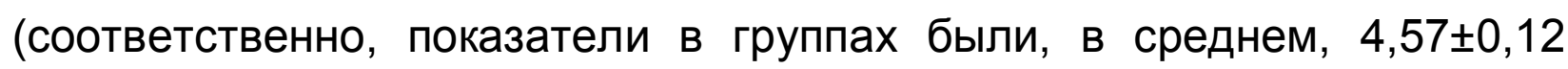

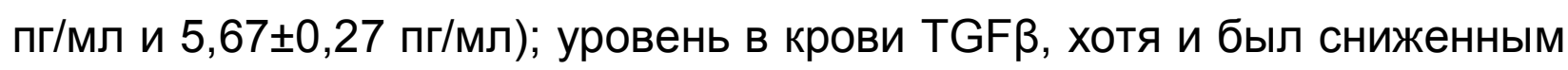

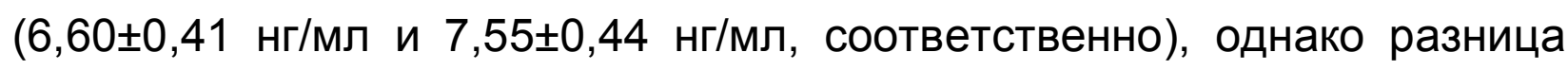
между исследуемыми группами была недостоверной ( $p>0,05)$ - рис. 1.

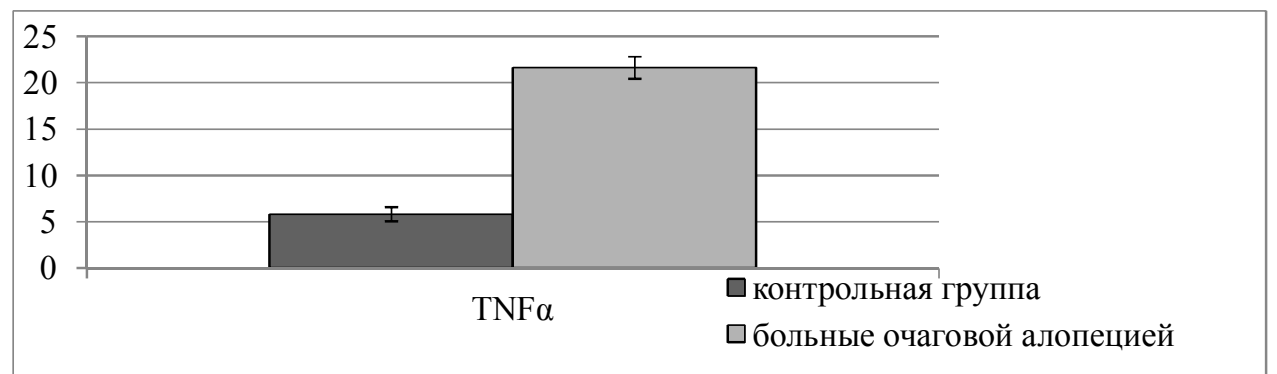



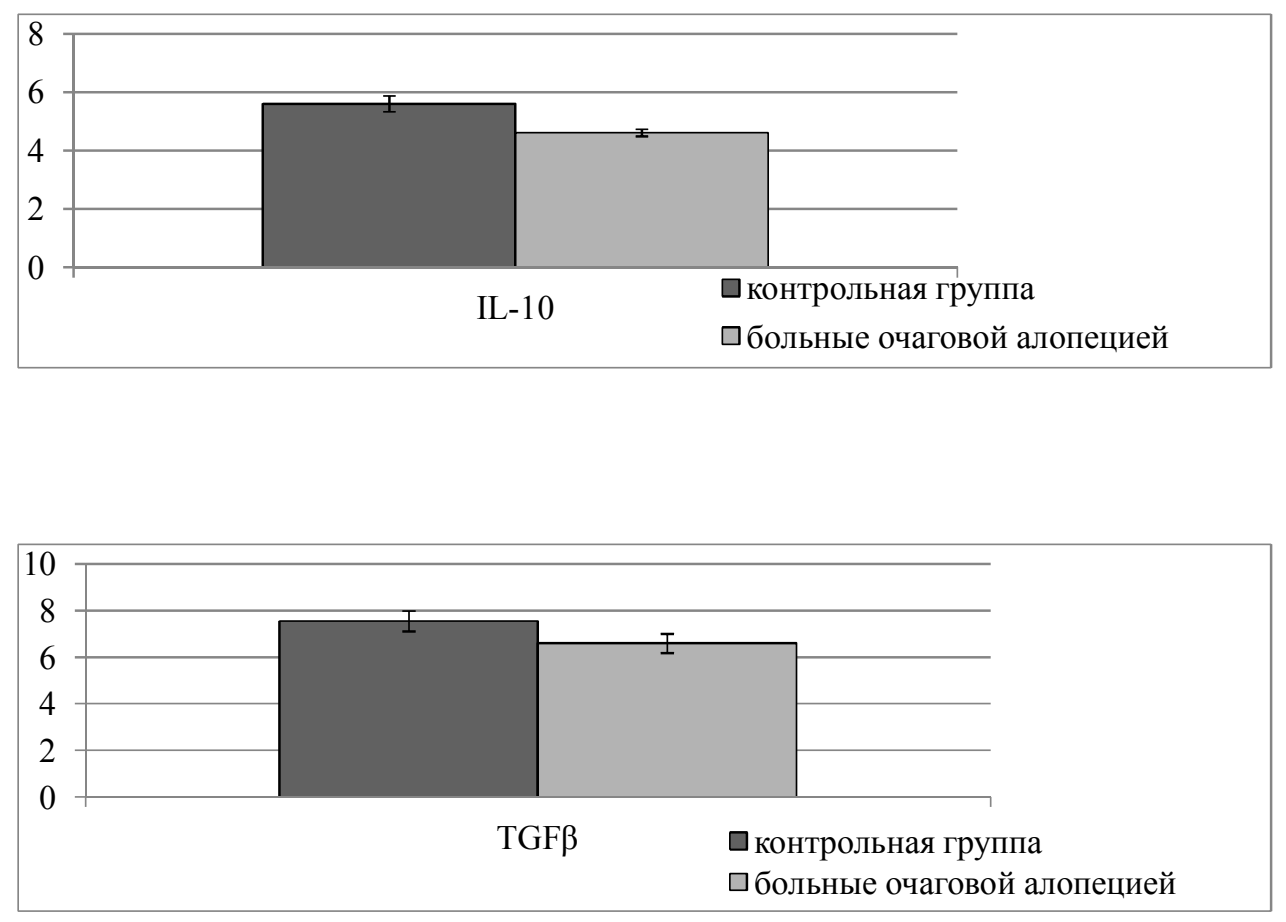

\section{Рис. 1. Содержание в крови TNF $\alpha$ (пг/мл), IL-10 (пг/мл) и TGF $\beta$ (в} нг/мл) у больных очаговой алопецией и лиц контрольной группы

Данные, представленные на рис. 1, могут свидетельствовать о следующем. Фактор некроза опухоли (TNFa), в основном. вырабатывается клетками, отвечающими за так называемый «неспецифический иммунитет» (моноцитами/макрофагами), а так же дендритными клетками и Th-лимфоцитами, и повышение его уровня в крови наблюдается при бактериальных и воспалительных процессах, в том числе - фрокальных; он также препятствует возникновению иммунной толерантности. Кроме того, TNFa обладает значительным провоспалительным эффектом; этот цитокин играет роль и при аутоиммунных реакциях. В то же время, если его блокада при ряде аутоиммунных заболеваний является эффективной, то использование ингибиторов TNFa при алопеции вызывает рецидив дерматоза [9]. При очаговой алопеции выявляется необычная экспрессия TNFa, которая в норме присутствует только во внутренней корневой сумке. Данный 
цитокин ингибирует и завершает рост волосяного фролликула, в зависимости от дозы, вызывает в культуре волосяных фолликулов образование дистрофических анагеновых волос, которые очень похожи на такие, которые наблюдаются при очаговой алопеции.

В отношении трансформирующего фрактора роста (TGF $\beta$ ), который в коже, в основном, продуцируется фрибробластами, большинство исследователей считает, что он ингибирует нормальное развитие волосяного фолликула и деление клеток матрикса, может вызывать катагеноподобные изменения в культуре волосяных фолликулов. Характер распределения этого фрактора роста и TNFa в условиях нормы позволяет предположить, что он является субстанцией постоянной секреции со стороны структур волосяного фолликула и может принимать участие в стимуляции постоянного деления эпителиоцитов и функционирования волосяного сосочка. При алопеции наблюдается отклонение от распределения данного фактора как в структурах волосяного фолликула, так и его микроокружения. Однако следует учитывать, что TGF $\beta$ принимает участие в поддержании так называемой «иммунной привилегии» в очаге, который окружает волосяной фолликул (для изоляции от антигенов, которые образуются в процессах, связанных со стадией анагена). Вышеуказанный принцип деятельности цитокиновой системы обозначается как «дублирование». Поэтому логично предположить, что на развитие аутоиммунного процесса влияют элементы обратной регуляции иммуного ответа, поскольку известно, что «выключение» гена TGF $\beta$ приводит к развитию генерализованной воспалительной реакции, в основе которой как раз и лежит аутоиммунный процесс.

Вместе с TGF $\beta$, в поддержании вышеуказанных феноменов «иммунной привилегии» волосяного фолликула и «обратной регуляции иммунного ответа», принимает участие и интерлейкин-10 (IL-10), 
который, в отличие от TNFa, считается цитокином, обеспечивающим наиболее выраженный противовоспалительный эффект. Основными клетками, которые его продуцируют, являются моноциты/макрофраги, Th2-лимфоциты и Т-регуляторные клетки - Treg. Таким образом, между продукцией провоспалительного цитокина TNFa и противовоспалительного цитокина IL-10 имеется патогенетическая связь - они синтезируются практически одними и теми же клетками одновременно, что соответствует современным взглядам на развитие воспалительно-репаративного процесса: реакции собственно «воспаления» и «репарации» начинаются практически одновременно (при алопеции - это т. н. «асептическое воспаление»). IL-10 не только имеет выраженное противовоспалительное свойство (ингибирует секрецию TNFa макрофагами и Th1-клетками), но и оказывает влияние на аутоиммунный процесс (стимулирует пролиферацию и активирует В-лимфоциты, ингибирует пролиферацию специфических Т-клеток, а также - синтез интерферона-гамма активированными киллерными лимфоцитами).

Таким образом, в коже при алопеции происходят выраженные изменения цитокинов, и это имеет важное значение, так как эти группы биологически активных молекул относятся к микрогормонам, преимущественно с локальным влиянием. Существует предположение и об общем изменении синтеза этих регуляторных фракторов при очаговой алопеции. Повышение синтеза цитокинов может приводить к нарушению нормальной пролиферации эпителиоцитов и преждевременному вхождению волоса в фразу анагена. При этом одним из факторов патогенеза алопеции могут быть нарушения соотношения синтеза цитокинов и фракторов роста. В то же время, исследования цитокинов и фракторов роста открывают достаточно 
противоречивые фракты их взаимного действия на рост волосяного стержня, клеток волосяного фолликула и дермального сосочка [10].

Статистический анализ наличия расстройств психофизиологического состояния у обследованных больных очаговой алопецией (в у. б.) показал, что пациентов с «легкой» степенью таких изменений (1 у. б.) было 10 (25\%), со «средней» (2 у. б.) - 25 (62,5\%),

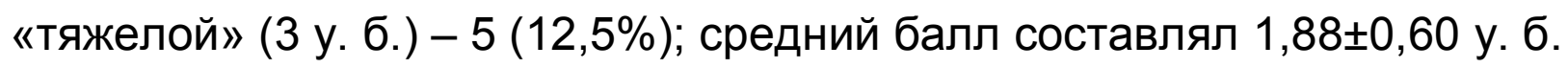

Кроме вышеуказанных данных о влиянии исследованных цитокинов на регуляцию работы волосяных фолликулов выявлены корреляционные связи изменений IL-10 и TNFa c показателями психофизиологического состояния больных (рис. 2).

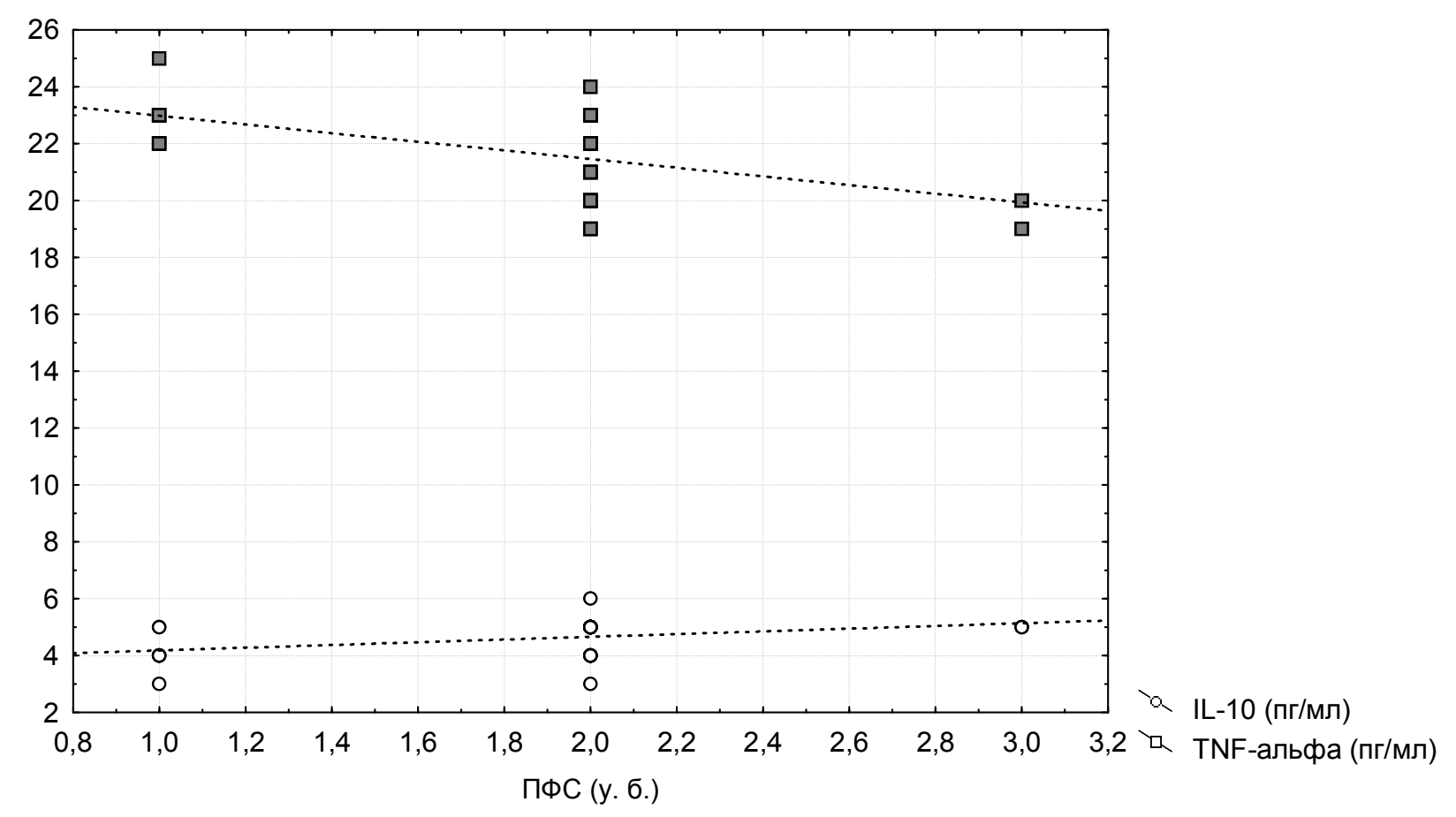

Рис. 2. Корреляционные связи между показателями психофизиологического состояния (ПФС) и уровнями содержания в крови IL-10 и TNFa у больных очаговой алопецией

Как свидетельствуют данные, приведенные на рис. 2, у обследованных больных очаговой алопецией между степенью изменений психофизиологического состояния и уровнем в крови IL-10 
имеет место «заметная прямая сила связи» (коэффрициент корреляции Спирмена - $r=0,38) ;$ для изменений уровня TNFa и психофизиологического состояния - «умеренная обратная сила связи» (коэффрициент корреляции Спирмена - r=-0,47).

Полученные результаты специальных исследований совпадают с данными литературы и свидетельствуют о существенной роли в патогенезе очаговой алопеции расстройств цитокиновой системы как на локальном, так и на общеорганизменном уровнях. Локально, со стороны синтезируемых эпителиоцитами волосяного фолликула и клетками микроокружения регуляторных молекул, создается патофизиологический круг с проявлениями нарушений роста эпидермоцитов и изменения физиологических фаз роста волосяного фолликула (эффректы влияния провоспалительного цитокина TNFa, противовоспалительных - IL10, TGF $\beta$ ). При условии «несрабатывания общих закономерностей функционирования цитокиновой молекулярной сети» («дублирование» функций, «синергизм», «аутокаталитичность» и др.) происходит потенцирование повреждающих эффректов и недостаточность компенсаторных механизмов. Прогрессирование алопеции становится мощным стрессовым фактором для больного человека и наличие невротических расстройств тревожно-депрессивного характера чаще проявляется в эмоциональной лабильности и раздраженности. У больных также имеют место повышенная реактивная и личностная тревожность, характер настроения - депрессивный с преобладанием вариабельно-лабильного типа, склонностью к дисфобиям и конфликтности, сложностях социального общения. Все эти изменения требуют комплексного подхода к их коррекции с учетом индивидуальных особенностей развития заболевания. 
Выводы. Данные иммуноферментных исследований содержания цитокинов в крови больных очаговой алопецией свидетельствуют о их влиянии на течение воспалительно-репаративного процесса при этом заболевании, переход волосяных фолликулов с фразы анагена в катаген и нарушения психофизиологического состояния пациентов, что диктует необходимость разработки патогенетически обоснованного комплексного метода их лечения с учетом выявленных изменений.

\section{Лumepamypa:}

1. Калюжна Л. Д. Хвороби похідних шкіри / Л. Д. Калюжна. К. : Грамота, 2008. -120 c.

2. Macdonald Hull S. P. Guidelines for the management of alopecia areata / S. P. Macdonald Hull, M. L. Wood, P. E. Hutchinson, M. Sladden, A. G. Messenger // British Journal of Dermatology. - 2003. - Vol. 149(4). P. 692-699.

3. Mirmirani P. Tinea capitis mimicking cicatricial alopecia: what host and dermatophyte factors lead to this unusual clinical presentation? / $P$. Mirmirani, I. J. Frieden, V. H. Price [et al.] // Journal of the American Academy of Dermatology. - 2009. - Vol. 60(3). - P. 490-495.

4. Price V. H. Therapy of alopecia areata: on the cusp and in the future / V.H. Price // Journal of Investigative Dermatology Symposium Proceedings. - 2003. - Vol. 8(2). - P. 207-211.

5. Костина С. В. Клиническое значение цитокинов при различных формах очаговой алопеции у детей / С. В. Костина, М. В. Хорева, A. C. Варивода [u дерматовенерологии, иммунологии и врачебной косметологии. 2009. - T. 2, № 2. - C. 5-9. 
6. The pathogenesis of alopecia areata in rodent models / K. J. Mc Elwee, P. Freyschmidt-Paul, J. P. Sundberg, R. Hoffmann // Journal of Investigative Dermatology. - 2003. - V. 8(1). - P. 6-11.

7. The progressive state, in contrast to the stable or regressive state of alopecia areata, is reflected in peripheral blood mononuclear cells / $M$. Zoller, K. J. Mc Elwee, M. Vitacolonna, R. Hoffmann // Experimental Dermatology. - 2004. - Vol. 13(7). - P. 435-444.

8. Коваленко І. В. Психосоматичні розлади: діагностика та лікування / І. В. Коваленко. - Вінниця: Консоль, 2005. - 32 с.

9. Tong $X$. Keratin 17 modulates hair follicle cycling in a TNFadependent fashion / X. Tong, P. A. Coulombe // Genes Dev. - 2006. - Vol. 20(10). - P. 1353-1364.

10.Пальчев М. А. Руководство по нейроиммуноэндокринологии / М. А. Пальцев, И. М. Кветной. - М.: Медицина, 2006. - 384 с.

\section{References:}

1. Kaljuzhna L. D. (2008). Hvoroby pohidnyh shkiry. Kyiv: Gramota. [in Ukrainian].

2. Macdonald Hull S. P., Wood M. L., Hutchinson P. E., Sladden M., Messenger A. G. (2003). Guidelines for the management of alopecia areata. British Journal of Dermatology, 149(4), 692-699. [in English].

3. Mirmirani P., Frieden I. J., Price V. H. et al. (2009). Tinea capitis mimicking cicatricial alopecia: what host and dermatophyte factors lead to this unusual clinical presentation? Journal of the American Academy of Dermatology, 60(3), 490-495. [in English].

4. Price V. H. (2003). Therapy of alopecia areata: on the cusp and in the future. Journal of Investigative Dermatology Symposium Proceedings, 8(2), 207-211. [in English].

5. Kostina S. V., Horeva M. V., Varivoda A. S. i dr. (2009). Klinicheskoe znachenie citokinov pri razlichnyh formah ochagovoj alopecii u detej. 
Sovremennye problemy dermatovenerologii, immunologii i vrachebnoj kosmetologii, 2(2), 5-9. [in Russian].

6. Mc Elwee K. J., Freyschmidt-Paul P., Sundberg J. P., Hoffmann R. (2003). The pathogenesis of alopecia areata in rodent models. Journal of Investigative Dermatology, 8(1), 6-11. [in English].

7. Zoller M., Mc Elwee K. J., Vitacolonna M., Hoffmann R. (2004). The progressive state, in contrast to the stable or regressive state of alopecia areata, is reflected in peripheral blood mononuclear cells. Experimental Dermatology, 13(7), 435-444. [in English].

8. Kovalenko I. V. (2005). Psyhosomatychni rozlady: diagnostyka ta likuvannja [Psychosomatic disorders: diagnosis and treatment]. Vinnitsa: Konsol'. [in Ukrainian].

9. Tong X., Coulombe R. A. (2006). Keratin 17 modulates hair follicle cycling in a TNFa-dependent fashion. Genes Dev., 20(10), 1353-1364. [in English].

10. Paltsev M. A., Kvetnoy I. M. (2006). Rukovodstvo po neyroimmunoendokrinologii. Moscow: Medicina. [in Russian].

Dermatovenerology and Cosmetology. - 2017. - 1(1). p. 24- 37 